\title{
ВЛИЯНИЕ НАНОЧАСТИЦ FЕЗО4 НА ОНТОГЕНЕЗ И МОРФОМЕТРИЧЕСКИЕ ПОКАЗАТЕЛИ КУКУРУЗЫ САХАРНОЙ (ZEA MAYS L.)
}

\section{INFLUENCE OF FE3O4 NANOPARTICLES ON THE ONTOGENESIS AND MORPHOMETRIC PARAMETERS OF ZEA MAYS L}

V. Kornienko

O. Kolchenko

A. Yaitsky

Summary. The paper studies the influence of magnetite nanoparticles stabilized with albumin on the ontogenesis and morphometric parameters of Zea mays L.As a result of the experiments, the concentration of nanoparticles was detected, which has a stimulating effect on the growth energy and entry of Zea mays $L$. seeds. It was found that when exposed to magnetite nanoparticles with a concentration of $2,4 \mathrm{mg} / \mathrm{ml}$, the energy of seed germination increased by $36 \%$, germination increased by $64 \%$, the length of seedlings increased by $24 \%$, and the root length increased by $78 \%$. Under the influence of vibration ( $10 \mathrm{~Hz}$ frequency) in the experimental group with a concentration of $2,4 \mathrm{mg} / \mathrm{ml}$ nanoparticles, the root length increased by $25 \%$, the root diameter decreased by $14 \%$, the stem length decreased by $2 \%$, and the stem diameter decreased by $1 \%$. In the group with a concentration of $1,6 \mathrm{mg} / \mathrm{ml}$, the stem diameter increased by $8 \%$. It was reliably established $(p<0,05)$ that the highest indicators of germination energy and germination of Zea mays $L$. were observed in the group with a concentration of magnetite nanoparticles of $2,4 \mathrm{mg} / \mathrm{ml}$. It is recommended to use magnetite nanoparticles with a concentration of $2,4 \mathrm{mg} / \mathrm{ml}$ without vibration as a growth stimulant for Zea mays L.

Keywords: Zea mays L.; nanoparticles; vibration; ontogenesis; morphometric parameters; agriculture; germination energy; germination.

\section{Введение}

XX века человечество активно стало применять наноматериалы и наночастицы (НЧ) в различных отраслях сельского хозяйства. Наиболее перспективными в своем применении являются наноматериалы из наночастиц железа и его оксидов в связи с их уникальными свойствами и предполагаемой малой токсичностью для живых организмов. Использование на-
Корниенко Владимир Олегович

Старший преподаватель, ГОУ ВПО «Донецкий национальный университет» kornienkovo@mail.ru

Кольченко Ольга Руслановна Аспирант, ГОУ ВПО «Донецкий национальный университет» daniaua411@gmail.com

Яицкий Андрей Степанович

Старший преподаватель, ФГБОУ ВО «Самарский государственный социально-педагогический университет» yaitsky@pgsga.ru

Аннотация. В работе представлены результаты исследования влияния наночастиц магнетита (Fе304), стабилизированных альбумином, на онтогенез и морфометрические показатели кукурузы сахарной (Zea mays L.). В результате проведенных экспериментов была определена концентрация наночастиц, оказывающая стимулирующее влияние на энергию роста и всхожесть семян кукурузы сахарной. Установлено, что при воздействии наночастиц магнетита с концентрацией 2,4 мг/мл, повысилась энергия прорастания семян на $36 \%$, всхожесть - на 64\%, увеличилась длина проростков на 24\%, длина корня на 78\%. Под влиянием вибрации (частотой 10 Гц) в экспериментальной группе с концентрацией наночастиц 2,4 мг/мл длина корней увеличилась на 25\%, диаметр корня уменьшился на $14 \%$, длина стебля уменьшилась на 2\%, его диаметр — на $1 \%$. В группе с концентрацией 1,6 мг/мл диаметр стебля увеличился на $8 \%$. Достоверно установлено $(p<0,05)$, что наиболее высокие показатели энергии прорастания и всхожести кукурузы сахарной наблюдались в группе с концентрацией 2,4 мг/мл. Рекомендовано использование наночастиц Fе304 с концентрацией 2,4 мг/ мл без воздействия вибрации в качестве стимулятора роста Zea mays $L$.

Ключевые слова: Zea mays L.; наночастицы; вибрация; онтогенез; морфометрические параметры; сельское хозяйство; энергия прорастания; всхожесть.

ночастиц открывает новые возможности для человека, но, с другой стороны, в силу своей малой изученности, представляют потенциальный риск для здоровья человека и окружающей среды и требуют дополнительных исследований [1]. Наночастицы обладают высокой адсорбционной ёмкостью, химической реакционной способностью и каталитической активностью [2]. Таким образом, наноматериалы используют в различных отраслях: промышленности, медицине и биологии, для монито- 
ринга качества окружающей среды, для биоремедиации почв и очистки сточных вод, для интенсификации сельского хозяйства [3].

Исследований, посвящённых использованию наночастиц в сельском хозяйстве, достаточно мало, по сравнению с исследованиями в биомедицинской отрасли. Однако известно, что наночастицы могут использоваться для прорастания семян, развития побегов и корней, повышения фотосинтетической активности, и для решения других сельскохозяйственных проблем. Так, предпосевная обработка семян кукурузы ультрадисперсным порошком железа повышала урожайность и способствовала снижению загрязнения зёрен кадмием и свинцом [4]. Данное явление объясняется более эффективной доставкой микроэлементов в ткани самого растения. При внесении микроэлементов в виде солей и хелатов используется лишь малая их часть. Доставка ионов через мембраны лимитируется количеством специализированных транспортных белков. Многие наночастицы из-за своих малых размеров не нуждаются в ионно-транспортном механизме и могут более эффективно доставлять микроэлементы в ткани и клетки растительного организма [3].

Наибольший интерес среди известных видов наночастиц представляет магнетит (Fe3O4). Кристаллическая решетка магнетита содержит атомы железа с разной валентностью - Fe(II) и $\mathrm{Fe}(\mathrm{III})$ [5]. Магнетит при комнатной температуре - ферримагнетик, но при размере частиц $<30$ нм он теряет постоянную намагниченность и проявляет суперпарамагнитные свойства, намагничиваясь только в магнитном поле, подобно парамагнетикам. Наночастицы оксидов железа менее токсичны, по сравнению с наночастицами кобальта и никеля. Они биосовместимы, довольно стабильны физически и химически, недороги в производстве, и их поведение легко контролировать магнитометрией. Поэтому данный тип наночастиц представляет наибольший интерес для применения в сельском хозяйстве. Однако, без специального покрытия наночастицы образуют устойчивые агрегаты, что негативно влияет на их магнитные свойства [6].

Механизмы и последствия трансформации и накопления наночастиц растениями пока мало изучены, так как результаты экспериментов достаточно противоречивы и зависят от множества факторов [7]. К таким факторам можно отнести как свойства наночастиц оксида железа, так и ростовой субстрат и видовую принадлежность растений [8]. Обладая высокой адгезией к корням, наночастицы могут оказывать физическое и химическое токсическое действие на растение. Оставаясь на поверхности эпидермиса и внедряясь в клетки корня, частицы могут закупоривать поры и ионные каналы, а потом модулировать поступление воды и минеральных ве- ществ в растения. Малый размер наночастиц позволяет им проникать даже через сосудистую ткань и распространяться на побег, перемещаясь через плазмодесмы [9]. Наночастицы также способны транспортироваться по апопласту и хелатироваться [10].

Большой интерес представляет также не однонаправленное действие наночастиц на растительный организм, а в комбинации с другими физическими или химическим факторами. Одним из распространенных физических факторов, влияющих на сельскохозяйственные растения, является вибрация. Вдоль загруженных автомагистралей она, посредством почвы, передаётся на довольно большие расстояния и влияет на рост и развитие сельскохозяйственных культур [11]. В процессе эволюции, растения выработали механизмы адаптации к воздействию стресса (механических стимулов, вибрации) [9; 12]. Процессы, лежащие в основе морфологических ответов растения на действие вибрации, остаются малоисследованными [13]. По результатам исследований [3], было выявлено, что, под влиянием механических колебаний на частотах 10-40 Гц, у кукурузы достоверно снижается длина стебля и корней. Незначительный стимулирующий эффект наблюдался на частоте 50 Гц [14].

Таким образом, актуальным является изучение как действия наночастиц в отдельности на растительный организм, так и в комбинации с другими факторами, которые способны снижать или повышать продуктивность и морфологические показатели сельскохозяйственных культур.

\section{Материал и метолы исслеАования}

Для исследования использовались семена кукурузы сахарной (Zea mays L.). Семена закладывались в ростовую камеру. В контрольных вариантах семенной материал замачивали в дистиллированной воде, экспериментальные группы обрабатывались суспензией НЧ металлов разных концентраций. После инкубации семян суспензию НЧ металлов сливали. Экспозиция составляла 2 часа. После чего семена помещались в чашки Петри по 50 семян на чашку, при этом подложкой для семян служила влажная фильтровальная бумага. Семена проращивали при температуре $+20^{\circ} \mathrm{C}$. Энергию прорастания и всхожесть семян определяли в сроки, указанные в ГОСТ 12038-84: на 3-е сутки (энергия прорастания) и 7-е сутки (всхожесть). Все эксперименты выполнялись не менее чем в трех повторностях и обрабатывались методами вариационной статистики с использованием пакета компьютерных программ «Statistica».

Для выполнения нашего исследования синтезировались магнитные наночастицы магнетита Fe304-ALB (частицы, стабилизированные альбуминовым покрытием). 


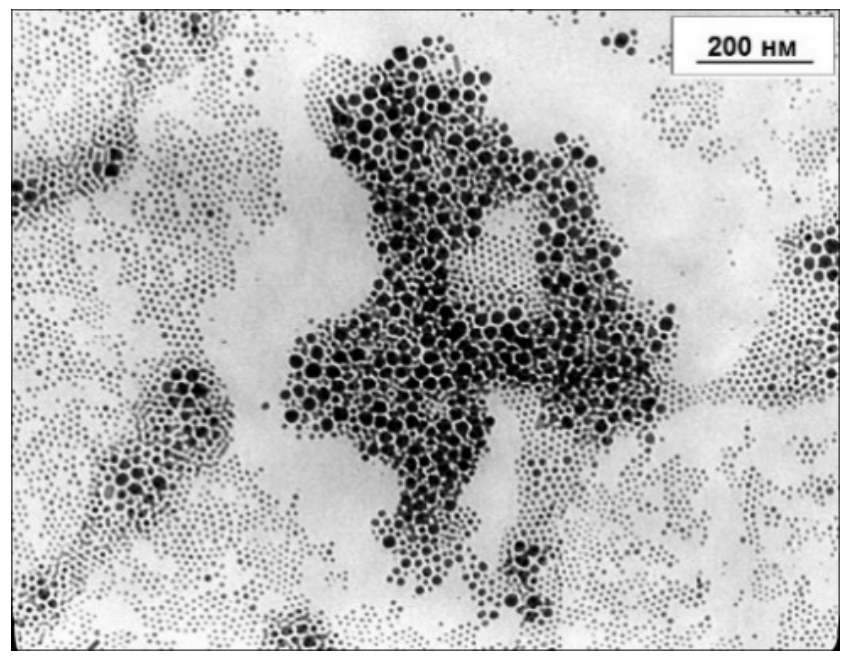

Рис. 1. Микрофотография наночастиц, стабилизированных альбуминовым покрытием

Синтез магнитных наночастиц осуществляли по аналогии с методикой, описанной в публикации [15]. Анализ образцов синтезированных наночастиц проводили с использованием электронной микроскопии.

Электронные микрофотографии магнитных наночастиц получали с помощью просвечивающего электронного микроскопа JEOL JEM 200A (рис. 1). Режим работы: ускоряющее напряжение 200 кВ, ток пучка 100 мкА, размер апертурной диафрагмы в режиме электронной дифракции - 0,1 мм. Пробирка с коллоидом магнитных наночастиц помещалась в ультразвуковой стакан (излучатель) с дистиллированной водой на 10 минут с удельной мощностью излучателя $50 \mathrm{Bт} / \mathrm{cm}^{2}$ и частотой излучения 35 кГц. Далее наносили на ультразвуковой излучатель с плоским наконечником и распыляли на тонкую углеродную пленку толщиной 10-20 нм, размещенную на специальной медной сеточке для просвечивающей электронной микроскопии.

Анализ электронных микрофотографий для определения линейных размеров магнитных наночастиц был выполнен с использованием инструментов программ AxioVision Rel. 4.8.

Концентрации НЧ Fe3О4 (СНЧ) составляли 0,8 мг/мл, 1,2 мг/мл, 1,6 мг/мл, 2,4 мг/мл.

Образцы кукурузы (зерновки) проращивались в ростовых камерах при соблюдении одинаковых освещённости, температуры, полива. Для предотвращения комбинированного действия химических веществ и вибрации, полив всех образцов кукурузы сахарной (зерновок) осуществлялся только дистиллированной водой 1 раз в сутки.
Закладка образцов (зерновок) и действие фактора происходили одновременно, т.е. воздействие техногенной вибрации моделировали с ранних стадий онтогенеза Zea mays L., исключая возможность набухания семени и дальнейшего его прорастания без воздействия механического стимула. Контрольные образцы были удалены от виброустановки и полива. Каждая серия в эксперименте и контроле имела выборку 50 шт.

Проращивание осуществлялось в течение 7 дней. На 3-й день проводили оценку энергии прорастания, на 7-й день оценивали морфометрические показатели и онтогенез.

В ходе эксперимента было сформировано 9 экспериментальных групп растений:

- I - контрольная - без обработки семян наночастицами и вибрацией;

- II - обработка семян наночастицами с концентрацией (СНЧ) 0,8 мг/мл;

- III - обработка семян наночастицами с CHЧ = 1,6 мг/мл;

- IV - обработка семян наночастицами с СНЧ = 2,4 мг/мл;

- $\mathrm{V}$ - обработка семян наночастицами с $\mathrm{CHY} \mathrm{=}$ $1,2 \mathrm{мг/мл;}$

- VI - обработка семян наночастицами с СНЧ = 1,2 мг/мл и воздействие на них вибрацией с частотой $f в и б p .=10$ Гц;

- VII - обработка семян наночастицами с СНЧ = 2,4 мг/мл и воздействие на них вибрацией с $f в u$ бр. = 10 Гц;

- VIII - обработка семян наночастицами с $C H Ч=$ 1,6 мг/мл и воздействие на них вибрацией с $f в u$ бр. = 10 Гц; 
Таблица 1. Онтогенетические изменения образцов Zea mays L. на 3-е сутки эксперимента (энергия роста)

\begin{tabular}{|l|l|l|l|}
\multirow{2}{*}{ Группы } & Фазы роста & набухшие & колеоптиль \\
\cline { 2 - 4 } & не проросшие & $24 \%$ & $56 \%$ \\
\hline I & $20 \%$ & $30 \%$ & $40 \%$ \\
\hline$I I$ & $30 \%$ & $62 \%$ & - \\
\hline IV & $38 \%$ & $36 \%$ & $64 \%$ \\
\hline$V$ & - & $54 \%$ & $12 \%$ \\
\hline$V I$ & $34 \%$ & $50 \%$ & $16 \%$ \\
\hline$V I I$ & $34 \%$ & $32 \%$ & $68 \%$ \\
\hline$V I I I$ & - & $64 \%$ & $36 \%$ \\
\hline IX & - & $80 \%$ & - \\
\hline
\end{tabular}

Таблица 2. Онтогенетические изменения образцов Zea mays L. на 7-е сутки

\begin{tabular}{|c|c|c|c|c|}
\hline \multirow{2}{*}{ Группа } & \multicolumn{4}{|c|}{ Фазы развития } \\
\hline & набухшие & колеоптиль & 1 лист & 2 листа \\
\hline I & $14 \%$ & $12 \%$ & $66 \%$ & $8 \%$ \\
\hline$\|$ & - & $24 \%$ & $58 \%$ & $18 \%$ \\
\hline III & $8 \%$ & $30 \%$ & $50 \%$ & $12 \%$ \\
\hline IV & - & $20 \%$ & $38 \%$ & $42 \%$ \\
\hline V & $30 \%$ & $36 \%$ & $16 \%$ & $18 \%$ \\
\hline VI & $18 \%$ & $68 \%$ & $14 \%$ & - \\
\hline VII & - & $44 \%$ & $42 \%$ & $14 \%$ \\
\hline VIII & - & $68 \%$ & $20 \%$ & $12 \%$ \\
\hline IX & - & $70 \%$ & $20 \%$ & $10 \%$ \\
\hline
\end{tabular}

- IX - обработка семян наночастицами с СНЧ = $0,8 \mathrm{mr/мл} \mathrm{и} \mathrm{воздействие} \mathrm{на} \mathrm{них} \mathrm{вибрацией} \mathrm{с} f в u$ бр. $=10$ Гц.

Вибрация частотой $f в и б р .=10$ Гц выбрана в связи с преобладанием низкочастотной вибрации в техногенно-загруженном регионе г. Донецка (автотранспорт, железнодорожный транспорт, промышленные предприятия).

После проведения экспериментальной части были выполнены измерения длины, диаметра стебля и корней контрольной и опытных групп штангенциркулем ШЦ-1 0-125 (0,05).

\section{Результаты исследования \\ и их обсужАение}

Влияние исследуемых факторов на онтогенетические показатели Zea mays L. Энергия прорастания семян кукурузы возрастает после обработки семян Нч разных концентраций, по сравнению с контролем. Однако после проведенного эксперимента эффективность воздействия отмечена не у всех групп. Не все обработан- ные семена кукурузы дали хорошую всхожесть, а некоторые совсем не дали ростков. Причиной этого послужили неблагоприятные условия (плохое освещение, низкая температура). Данные приведены в табл. 1.

Из полученных данных на 3-е сутки видно, что лучше всего проросли семена групп IV и VII. Данные группы находились в одной концентрации наночастиц железа ( $C H Ч=2,4$ мг/мл), но VII группа дополнительно подвергалась вибрации $(f в u б p .=10$ Гц). Количество проросших семян в группе VII превышает соответствующий показатель как группы без влияния вибраций, так и контрольной группы. Таким образом, данная концентрация повлияла на прорастание кукурузы положительно. На основе полученных данных построена гистограмма (рис. 2) онтогенетического изменения образцов Zea mays L.

Как видно из рис. 2, наибольшее количество набухших семян - в IX группе $(C H Ч=0,8$ мг/мл; $f в и б p .=10$ Гц $)$, наименьшее - в I группе (контрольной). Наибольшее количество непроросших семян кукурузы сахарной отмечено в III группе (CHЧ = 1,6 мг/мл), а наименьшее - в I группе и в IX группе $(C H U=0,8$ мг/мл; $f в и б p .=10$ Гц), и в группах IV, VII и VIII, где непроросших семян не наблюдалось. Ста- 
Таблица 3. Значения средней длины и диаметра для стеблей и корней исследуемых групп Zea mays L.

\begin{tabular}{|l|l|l|l|l|}
\multirow{2}{*}{ Группа } & \multicolumn{2}{l|}{ Стебель } & Корень & d, мм \\
\cline { 2 - 5 } & $l$, см & $d$, мм & $l$, см & $1,20 \pm 0,19$ \\
\hline $\mathrm{I}$ & $5,60 \pm 2,30$ & $2,40 \pm 0,70$ & $4,40 \pm 0,53$ & $0,95 \pm 0,27$ \\
\hline $\mathrm{II}$ & $4,90 \pm 2,90$ & $2,20 \pm 0,90$ & $4,47 \pm 1,54$ & $0,84 \pm 0,20$ \\
\hline $\mathrm{IV}$ & $2,94 \pm 1,42$ & $2,08 \pm 0,75$ & $3,00 \pm 0,40$ & $1,10 \pm 0,11$ \\
\hline $\mathrm{V}$ & $6,90 \pm 2,01$ & $2,40 \pm 0,44$ & $7,80 \pm 3,13$ & $0,52 \pm 0,30$ \\
\hline $\mathrm{VI}$ & $2,98 \pm 2,50$ & $1,57 \pm 1,00$ & $1,90 \pm 1,20$ & $1,24 \pm 0,16$ \\
\hline $\mathrm{VII}$ & $4,27 \pm 2,81$ & $2,14 \pm 0,54$ & $3,41 \pm 0,71$ & $1,03 \pm 0,08$ \\
\hline $\mathrm{VIII}$ & $5,47 \pm 1,30$ & $2,36 \pm 0,30$ & $5,47 \pm 1,63$ & $0,73 \pm 0,46$ \\
\hline $\mathrm{IX}$ & $4,84 \pm 3,00$ & $2,59 \pm 1,52$ & $4,29 \pm 2,32$ & $0,52 \pm 0,30$ \\
\hline
\end{tabular}

Таблица 4. Относительные значения средней длины и диаметра стебля и корня исследуемых групп Zea mays L.

\begin{tabular}{|l|l|l|l|l|}
\multirow{2}{*}{ Группа } & Стебель & Корень & \multicolumn{1}{l|}{} \\
\cline { 2 - 5 } & $\mathbf{I}$ & $\mathbf{d}$ & $\mathbf{I}$ & $\mathbf{d}$ \\
\hline $\mathrm{I}$ & 1,00 & 1,00 & 1,00 & 1,00 \\
\hline $\mathrm{II}$ & 0,88 & 0,92 & 1,02 & 0,80 \\
\hline $\mathrm{IV}$ & 0,53 & 0,87 & 0,69 & 0,70 \\
\hline $\mathrm{V}$ & 1,24 & 1,00 & 1,78 & 0,92 \\
\hline $\mathrm{VI}$ & 0,54 & 0,63 & 0,44 & 0,44 \\
\hline $\mathrm{VII}$ & 0,77 & 0,90 & 0,78 & 1,04 \\
\hline $\mathrm{VIII}$ & 0,98 & 0,99 & 1,25 & 0,86 \\
\hline $\mathrm{IX}$ & 0,87 & 1,08 & 0,98 & 0,61 \\
\hline
\end{tabular}

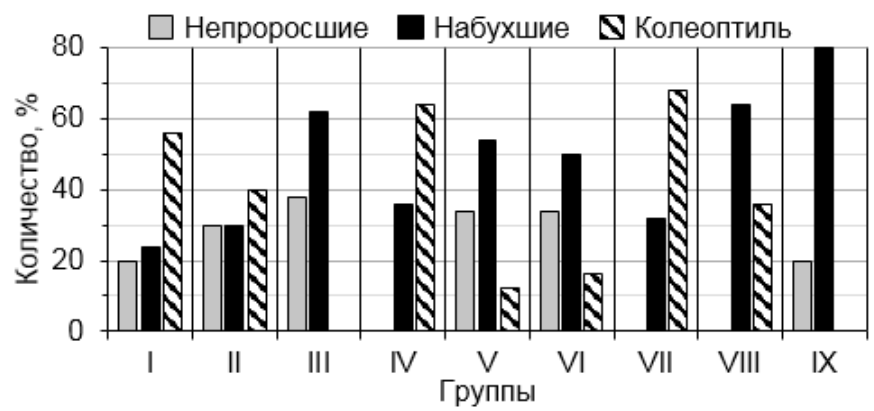

Рис. 2. Онтогенетические изменения образцов Zea mays L. на 3-е сутки

дия колеоптиля преобладает в IV (CHЧ = 2,4 мг/мл) и в VII $(C H \Psi=2,4$ мг/мл; fвибр. = 10 Гц $)$ группах.

Стимулирующее действие НЧ наблюдается у IV и VII групп, т.к. их показатель прорастания превышает контрольную группу. Остальные группы являются ингибиторными: их показатели меньше контрольной.

На 7-е сутки были сняты показания фаз развития. Все данные занесены в табл. 2.

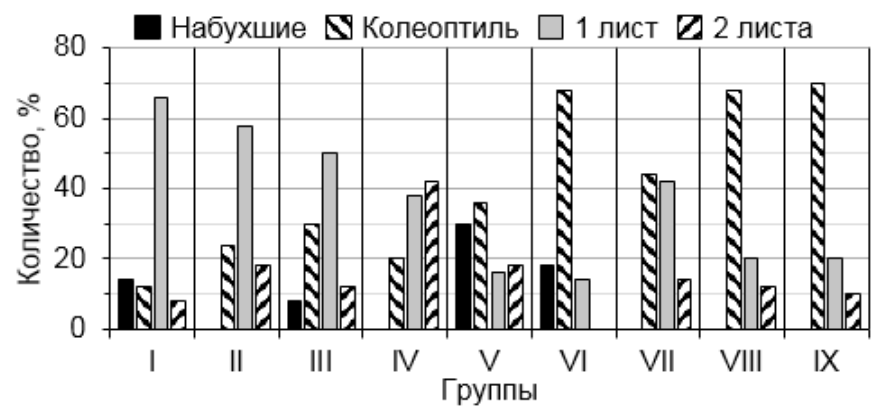

Рис. 3. Онтогенетические изменения образцов Zea mays L. на 7-е сутки

По данным таблицы построена диаграмма, показывающая, какую степень всхожести имеет кукуруза на седьмые сутки (рис. 3).

По рис. 3 видно, что наибольшее количество семян находятся в стадии колеоптиля в IX группе (70\%), наименьшее - в контрольной группе (12\%). Группа, у которой преобладают два листа,- IV (42\%), а наименьшее значение наблюдается у контрольной группы I и у группы VI, где второй лист отсутствовал. Опытные образцы, 
у которых преобладает один лист,- контрольная группа I (66\%), а наименьшее значение отмечается в VI группе (14\%). Можно сделать вывод, что наилучшими показателями обладает IV группа ( $C_{H \Psi}=2,4$ мг/мл).

Влияние исследуемых факторов на морфометрические показатели Zea mays L. B ходе исследования было изучено влияние вибрации и наночастиц магнетита различных концентраций на морфометрические параметры Zea mays L.: длину и диаметр вегетативных органов - стебля и корня. Основные результаты занесены в табл. 3.

Так как эксперименты проводились в течение длительного времени, для удобства сравнения результаты, полученные в группах II-IX, относили к результатам контрольной группы:

$d=d$ среднее опыт / $d$ среднее контроль;

$l=l$ среднее опыт / $l$ среднее контроль.

Влияние механических колебаний на длину стебля и корней кукурузы оказалось незначительным. Так, статистически значимое увеличение средних длин стебля кукурузы происходило в IV группе $\left(C_{H \Psi}=\right.$ 2,4 мг/мл), корня также в IV группе $\left(C_{H \Psi}=2,4\right.$ мг/мл), II группе $\left(C_{H \Psi}=0,8 \mathrm{mr} / \mathrm{m} л\right), \mathrm{VII}$ группе $\left(C_{H \Psi}=2,4 \mathrm{mr} /\right.$ мл; $f в и б p .=10$ Гц $)$ и в VIII группе $\left(C_{H ч}=1,6\right.$ мг/мл; $f в u$ $б p .=10$ Гц). Влияние вибрации на растения в меньшей степени отразилось на значениях среднего диаметра корней.

Как видно из табл. 4, увеличение длины стебля, в сравнении с контрольной группой, происходит в IV опытной группе $\left(C_{H \Psi}=2,4 \mathrm{mг} / \mathrm{Mл}\right)$, а диаметра - в VIII группе $\left(C_{H ч}=1,6\right.$ мг/мл; $f_{\text {вибр. }}=10$ Гц). Остальные группы имеют значения меньше контрольной группы, а это зна- чит, что факторы, влияющие на них, оказывают ингибиторное воздействие.

Длина корня, в сравнении с контрольной группой, возросла во II группе ( $C_{H \Psi}=0,8$ мг/мл), IV $\left(C_{H \Psi}=2,4\right.$ мг/мл) и VII $\left(C_{H ч}=2,4\right.$ мг/мл; fвибр. $=10$ Гц $)$. Диаметр корня увеличился лишь в VI группе $\left(C_{H ч}=1,2 \mathrm{мг/мл;}\right.$ $f_{\text {вибр. }}=10$ Гц).

\section{Зак^ючение}

При использовании НЧ железа концентрации 2,4 мг/мл, повысилась энергия прорастания семян кукурузы сахарной на 36\%, всхожесть - на 64\%, увеличилась длина проростков на 24\%, длина корня на 78\%. Ингибирующий эффект спровоцировали концентрации наночастиц 1,2 мг/мл ( $d$ стебля меньше относительно контрольной группы на $37 \%, l$ стебля - 46\%, $l$ корня - 56\%, $d$ корня - 56\%) и 1,6 мг/мл ( $d$ стебля меньше на $13 \%, l$ стебля $-47 \%, l$ корня $-31 \%, d$ корня $-30 \%)$.

Установлено, что под влиянием вибрации (частота 10 Гц) в группе с концентрацией наночастиц магнетита 2,4 мг/мл, относительно контрольной группы, увеличилась длина корней на 25\%, диаметр корня уменьшился на 14\%, длина стебля уменьшилась на $2 \%$, так же, как и его диаметр - на 1\%. В экспериментальной группе с концентрацией 1,6 мг/мл увеличился диаметр стебля на $8 \%$.

Достоверно установлено ( $<<0,05)$, что высокие показатели прорастания и всхожести кукурузы сахарной наблюдались в группе с концентрацией 2,4 мг/мл. Таким образом, может служить рекомендацией возможность использования наночастиц железа с концентрацией 2,4 мг/мл без воздействия вибрации в качестве стимулятора роста Zea mays L.

\section{ЛИТЕРАТУРА}

1. Постановление Главного государственного санитарного врача РФ от 31.10.2007 № 79 «0б утверждении Концепции токсикологических исследований, методологии оценки риска, методов идентификации и количественного определения наноматериалов».

2. Мазуренко В. В., Руденко А. Н., Мазуренко В.Г. Наночастицы, наноматериалы, нанотехнологии: уч. пособие. Екатеринбург, 2009.83 с.

3. Анохина Т. О., Сиунова Т. В., Сизова 0. И., Кочетков В. В., Боронин А. М. Свойства наночастиц оксидов железа и проблемы их применения в сельском хозяйстве // Агрохимия. 2017. № 11. С. 74-96.

4. Еськов Е. К., Еськова М. Д., Чурилов Г.И. Способ повышения экологической безопасности семенного урожая в техногеннозагрязненных агроценозах: Пат. 2463758, PФ, A 01 C1/00. 2012.

5. Hasany S.F, Ahmed I., Rajan J., Rehman A. Systematic review of the preparation techniques of iron oxide magnetic nanoparticles // Journal of Nanoscience and Nanotechnology. 2012. Vol. 2. P. 148-158.

6. Wu W., Wu Z., Yu T., Jiang C., Kim W.-S. Recent progress on magnetic iron oxide nanoparticles: synthesis, surface functional strategies and biomedical applications // Science and Technology of Advanced Materials. 2015. Vol. 16. P. 1-43. D0I: 10.1088/1468-6996/16/2/023501.

7. Deng Y., White J.C., Xing B. Interactions between engineered nanomaterials and agricultural crops: implications for food safety // Journal of Zhejiang University Science A (Applied Physics \& Engineering). 2014. Vol. 15. P. 552-572. D0l: 10.1631/jzus.A1400165.

8. Pardha-Saradhi P., Yamal G., Peddisetty T., Sharmila P., Singh J., Nagarajan R. Plants fabricate Fe-nanocomplexes at root surface to counter and phytostabilize excess ionic Fe // BioMetals. 2014. Vol. 27. P. 97-114. D0I: 10.1007/s10534-013-9690-7. 
9. Khot L. R., Sankaran S., Maja J. M., Ehsani R., Schuster E. W. Applications of nanomaterials in agricultural production and crop protection: a review // Crop Protection. 2012. Vol. 35. P. 64-70. D0l: 10.1016/j.cropro.2012.01.007.

10. Ghafarian M. H., Malakouti M. J., Dadpour M. R., Stroeve P., Mahmoudi M. Effects of magnetite nanoparticles on soybean chlorophyll // Environmental Science and Technology. 2013. Vol. 47(18). P. 10645-10652. D0I: 10.1021/es402249b.

11. Braam J. In touch: plant responses to mechanical stimuli // New Phytologist. 2005. Vol. 165, is. 2. P. 373-389. D0I: 10.1111/j.1469-8137.2004.01263.x.

12. Капшуков Р. А., Ткаченко Д. С., Симонова Е. О. Магнитные и электронно-микроскопические исследования магнитных наночастиц Ғезо4 с альбуминовым покрытием // Донецкие чтения 2019: образование, наука, инновации, культура и вызовы современности: мат-лы IV междунар. науч. конф. Т. 2. Донецк: Изд-во ДонНУ, 2019. С. 171-174.

13. Lee D., Polisensky D. H., Braam J. Genome-wide identification of touch- and darkness-regulated Arabidopsis genes: a focus on calmodulin-like and XTH genes // New Phytologist. 2005. Vol. 165, is. 2. P. 429-444. D0l: 10.1111/j.1469-8137.2004.01238.x.

14. Chehab E. W., Yao C., Henderson Z., Kim S., Braam J. Arabidopsis touch-induced morphogenesis is jasmonate mediated and protects against pests // Current Biology. 2012. Vol. 22, is. 8. P. 701-706.

15. Корниенко В. О., Тарабарова А. Г. Влияние вибрации частотой 10-50 Гц на ростовые показатели кукурузы сахарной (Zеa mays L.) // Проблемы экологии и охраны природы техногенного региона. 2017. № 1. С. 108-115.

16. Ткаченко Д. С., Легенький Ю. А. Модифицированная методика синтеза наночастиц с альбумином для магнитной модификации живых клеток // Донецкие чтения 2019: образование, наука, инновации, культура и вызовы современности: мат-лы IV междунар. науч. конф. Т. 2. Донецк: Изд-во ДонНУ, 2019. C. 184-186.

( Корниенко Владимир Олегович ( kornienkovo@mail.ru ),

Кольченко Ольга Руслановна ( daniaua411@gmail.com ), Яицкий Андрей Степанович ( yaitsky@pgsga.ru ).

Журнал «Современная наука: актуальные проблемы теории и практики»

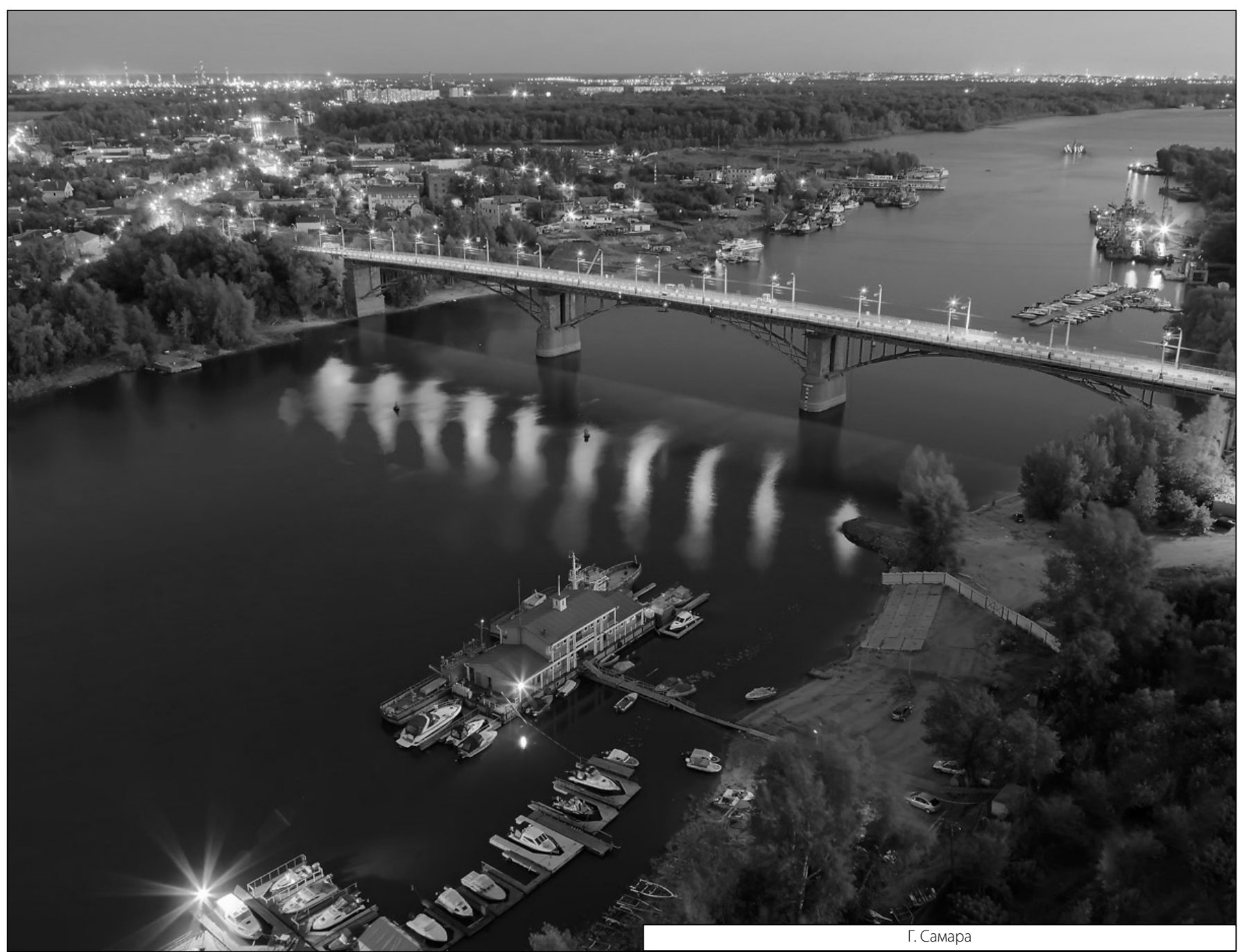

